\title{
Both N-terminal and C-terminal regions of steroid sulfatase are important for enzyme activity
}

\author{
T Sugawara, E Nomura ${ }^{1}$ and $\mathbf{N}$ Hoshi $^{2}$ \\ Department of Biochemistry and 'Department of Obstetrics \& Gynaecology, Hokkaido Graduate School of Medicine, Kita-ku, Kita 15, Nishi 7, \\ Sapporo 060-8638, Japan \\ ${ }^{2}$ Department of Animal Science, Faculty of Agriculture, Kobe University, Kobe 657-8501, Japan \\ (Requests for offprints should be addressed to T Sugawara; Email: terusuga@med.hokudai.ac.jp)
}

\begin{abstract}
Steroid sulfatase (STS) is localized in the endoplasmic reticulum and catalyzes desulfation of $3 \beta$-hydroxysteroid sulfates. X-linked ichthyosis (XLI) is an inherited skin disorder caused by deficiency of STS enzyme activity. We previously reported a case in which XLI with a one-base change in the STS gene and variation in amino acid Q560P developed. In this study, we performed molecular analysis to determine the importance of terminal regions of STS and the effect of mutant STS on STS enzyme activity. To examine the effect of terminal truncated STS on the enzyme activity, N- and C-terminal truncated STS expression vectors were transfected into COS-1 cells. The activity of truncated STS lacking the N-terminal regions declined, and the activity of C-terminal-truncated STS declined with extension of the truncated C-terminal
\end{abstract}

region. Although the results of pulse-chase experiments showed that a one-base mutant STS (Q560P) and C-terminal-truncated STS ( $\triangle \mathrm{C} 2(1-559))$ had no effects on protein synthesis and degradation, the mutant STS and C-terminal-truncated STS have dominant negative effect on STS enzyme activity when the STS mutant or truncated STS protein and a wild-type STS protein coexist in cells. Results of coprecipitation of the truncated STS with an STS-FLAG fusion protein showed that STS formed a dimer conformation in cells. In this study, we have shown that both the $\mathrm{N}$-terminal region and $\mathrm{C}$-terminal region are important for STS enzyme activity. The C-terminal mutant has a dominant negative effect on wild-type STS. Journal of Endocrinology (2006) 188, 365-374

\section{Introduction}

Steroid sulfatase (STS) (EC 3.I.6.2) is present in various mammalian tissues, such as the liver, ovary and testis, and is especially abundant in the placenta (Warren \& French 1965). This enzyme is a membrane-bound protein that is localized in the endoplasmic reticulum (ER) and catalyzes desulfation of cholesterol sulfate and $3 \beta$-hydroxysteroid sulfates, such as progesterone sulfate, dehydroepiandrosterone sulfate and estrone sulfate (Willemsen et al. 1988, Stein et al. 1989). The sulfated forms of steroid hormones, which are inactive because of their failure to bind to their receptors, become active after desulfation by STS (Warren \& French 1965). STS has been purified from microsomal fractions of tissues with detergents (Gauthier et al. 1978). Although the molecular mass of STS determined by SDS-PAGE is $63 \mathrm{kDa}$, STS seems to be a $126 \mathrm{kDa}$ protein from its active appearance determined by gel-filtration analysis (Noel et al. 1983). Digestion of STS by endoglycosidase $\mathrm{H}$ has shown that STS has two N-glycosylation sites (Stein et al. 1989).

$\mathrm{X}$-linked ichthyosis (XLI) is an inherited skin disorder caused by a deficiency of STS enzyme activity. Lack of
STS enzyme activity results in an excessive amount of epidermal cholesterol sulfate in the epidermis and alterations in the physical properties of corneocytes (Elias et al. 1984, Zettersten et al. 1998). XLI is characterized by a generalized scaling of the skin, with large, polygonal, dark-brown scales. XLI has been diagnosed by assaying STS activity in the placenta of the patient's mother or in the lymphocytes of the patient after birth (Traupe \& Ropers 1982). The STS gene has been cloned, and it has been found that most patients with XLI have large deletions of the STS gene (Yen et al. 1987, Shapiro et al. 1989, Stein et al. 1989). However, point mutations in the STS gene have been reported in some XLI patients with complete STS deficiency (Alperin \& Shapiro 1997). We previously reported two cases with a one-base change in the STS gene, and variations in amino acids Q560P and H444R were found in those cases (Sugawara et al. 2000). The finding of impairment of STS enzyme activity in a Q560P mutant in the C-terminal region of STS indicates that the C-terminal region of the STS enzyme is important for STS enzymatic function (Sugawara et al. 2000). In this study, we performed molecular analysis of both 


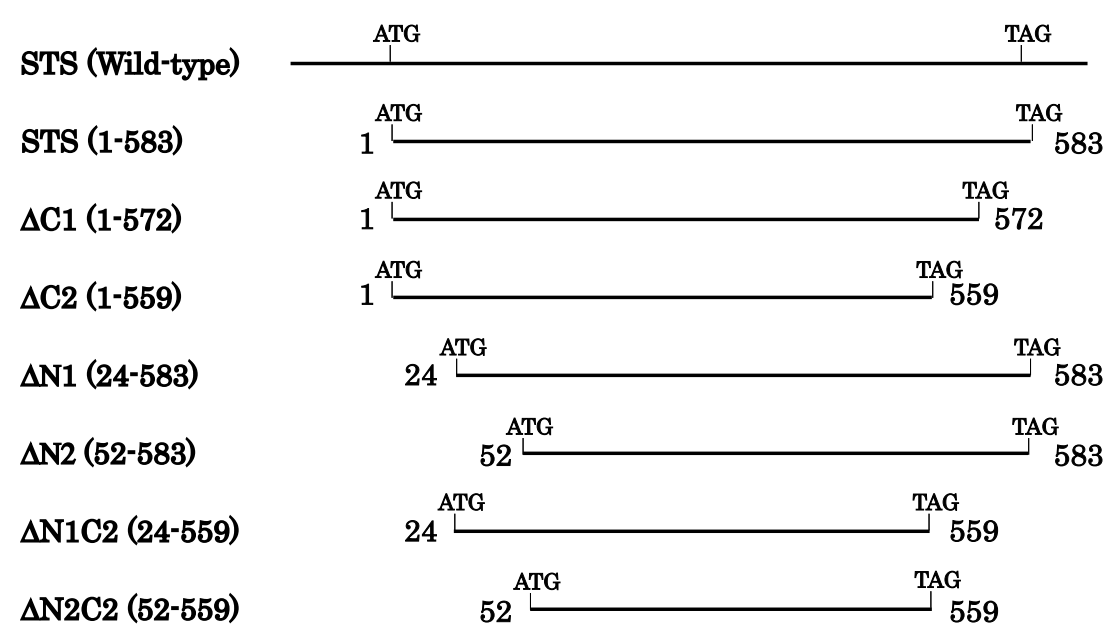

Figure 1 Artificial truncated STS mutant proteins. $\Delta \mathrm{C} 2$ lacks the $\mathrm{C}$-terminal region of the STS protein including glutamine of codon 560. $\Delta \mathrm{N} 1$ lacks the first $\mathrm{N}$-terminal 24 amino-acid residues encoding a signal peptide from wild-type STS. $\Delta \mathrm{N} 2$ lacks the first 52 $\mathrm{N}$-terminal amino acids that include an $\mathrm{N}$-glycosylation site, the residue of which is asparagine codon 47. Wild-type STS has 583 amino acids. STS cDNA and mutant STS cDNA were inserted into a pSV-SPORT-1 expression vector to express the truncated STS protein.

terminal regions of the STS protein and clarified the effect of a mutant STS protein on wild-type STS protein.

\section{Materials and Methods}

\section{Plasmid constructs}

Human STS cDNA $(2 \cdot 0 \mathrm{~kb})$ encoding a full-length STS protein expression vector (pSTS) was prepared by inserting an EcoRI fragment from human STS cDNA into pSV.SPORT-1 (Sugawara et al. 2001). We previously reported a case of XLI with a one-base change in the STS gene and variation in amino acid Q560P, a mutant lacking STS enzyme activity (Sugawara et al. 2000). Q560P mutation was produced with a Transformer Site Directed Mutagenesis kit (Clontech) to yield the plasmid Q560P, as described previously (Sugawara et al. 2001). STS has N-terminal signal peptides of 23 amino acids, which start with a methionine and an N-glycosylation site at asparagine residue 47 in the $\mathrm{N}$-terminal region. Various truncated STS expression constructs were prepared by PCR using human STS cDNA as a template and were cloned into pSV-SPORT1 at EcoRI restriction enzyme sites. The truncated STS proteins are illustrated in Fig. 1. ATG was added to the N-terminal region of the truncated STS mutant so that the mutant translates from methionine, and the terminal codon TAG was also added to the C-terminal region of the truncated STS mutant. STS (1-583), which lacks the $5^{\prime}$ - and $3^{\prime}$-untranslated regions of the STS gene, encodes the full length of STS protein. $\triangle \mathrm{C} 1$ (1-572) lacks 11 C-terminal amino acids, and $\triangle \mathrm{C} 2(1-559)$ lacks $24 \mathrm{C}$-terminal amino acids, including glutamine 560. $\triangle \mathrm{N} 1 \quad(24-583)$ lacks the first 24 N-terminal amino acids that encode a signal peptide to microsomes, and $\triangle \mathrm{N} 2 \quad(52-583)$ lacks the first 52 $\mathrm{N}$-terminal amino acids that include an $\mathrm{N}$-glycosylation site, codon 47 (Asn). $\triangle \mathrm{N} 1 \mathrm{C} 2 \quad(24-559)$ lacks the N-terminal 24 amino acids and the C-terminal 24 amino acids, and $\triangle \mathrm{N} 2 \mathrm{C} 2(52-559)$ lacks the N-terminal 52 amino acids and the C-terminal 24 amino acids. To produce an STS and C-terminal FLAG fusion protein, which is called an STS-FLAG fusion protein expression vector, an EcoRI fragment of the human STS cDNA was amplified by PCR from pSTS and cloned into the $\mathrm{p} 3 \mathrm{x}$ FLAG vector (Sigma).

\section{Cell culture and transfection}

Monkey kidney COS-1 cells were obtained from RIKEN Bank (Tsukuba, Japan). COS-1 cells were grown in $35 \mathrm{~mm}$ plastic dishes and cultured in Dulbecco's Modified Eagles' Medium (DMEM) supplemented with $10 \%(\mathrm{v} / \mathrm{v})$ fetal calf serum (FCS) and $50 \mu \mathrm{g} / \mathrm{ml}$ gentamycin. COS-1 cells were transfected with wild-type STS cDNA and truncated mutant STS cDNA expression vectors, using FuGENE 6 (Roche), as described previously (Sugawara et al. 2001). Some cultures were cotransfected with wild-type STS cDNA and truncated mutant STS. The cells were allowed to incubate for $48 \mathrm{~h}$. At the end of the culture, extracts were collected for evaluation of STS enzyme activity and for Western blotting. The cells were washed twice with PBS, and 
cell extracts were prepared in $200 \mu \mathrm{l}$ STS lysis buffer $(10 \mathrm{mM}$ Tris $-\mathrm{HCl}, 1 \%(\mathrm{v} / \mathrm{v})$ Triton-X, $1 \times$ proteinase inhibitor (Roche)). Protein concentration was determined with a BCA protein assay kit (Pierce, Rockford, IL, USA). Each experiment was performed on at least three separate occasions with three different cell preparations to confirm the generality of the findings.

\section{STS enzyme activity}

STS enzyme activity was assayed by the previously described method (Sugawara et al. 1994). The reaction mixture, which contained $20 \mathrm{mM}$ Tris-HCI ( $\mathrm{pH} 8.0$ ), 50000 d.p.m. of 7-[ $\left[{ }^{3} \mathrm{H}\right]$ dehydroepiandrosterone sulfate (DHEAS) (16 Ci/mmol; New England Nuclear, Boston, MA, USA), 100 pmol DHEAS, 1\% (v/v) Triton-X-100 and $25 \mu \mathrm{l}$ cell extracts, was incubated at $37^{\circ} \mathrm{C}$ for $1 \mathrm{~h}$. At the end of incubation, desulfated DHEA was extracted by the addition of benzene and was assayed by a liquid scintillation counter after adding $3 \mathrm{ml}$ scintillation mixture. One unit of activity was defined as the amount of enzyme that catalyzes the hydrolysis of 1 pmol DHEAS per h/mg.

\section{Western blot analysis}

Cultures of subconfluent COS-1 cells were plated so that $35 \mathrm{~mm}$ tissue culture dishes received equal numbers of cells. COS-1 cell extracts were harvested for Western blot analysis after transfection. An amount of $10 \mu \mathrm{g}$ cell extract was then subjected to SDS-PAGE. After electrophoresis, the gels were transferred to nitrocellulose membranes for immunodetection with rabbit anti-STS serum, which was prepared by immunization of rabbits with human STS, as described previously (Sugawara et al. 1994). Rabbit polyclonal anti-STS serum was used as a primary antibody at a dilution of 1:1000. After incubation for $1 \mathrm{~h}$ at $25^{\circ} \mathrm{C}$, the blot was further incubated for $60 \mathrm{~min}$ at $25^{\circ} \mathrm{C}$ with horseradish peroxidase-conjugated affinity pure goat antirabbit antibody (Roche) at a dilution of 1:10 000. The signal was detected by chemiluminescence with ECL Western blotting detection reagents (Amersham Pharmacia Biotech). The membrane was then exposed to RX-U film (Fuji, Tokyo, Japan).

\section{Northern blot analysis and preparation of a $\mathrm{cDNA}$ probe}

COS-1 cells were cultured for 1 day after being subcultured in $100 \mathrm{~mm}$ plastic dishes and were then transfected with various kinds of pSTS and truncated mutant STS cDNA expression vectors using FuGENE 6. The protocols for the preparation, culture and isolation of total RNA from COS-1 cells have been described in detail previously (Sugawara \& Fujimoto 2004). For Northern blot analysis, $30 \mu \mathrm{g}$ total RNA from each dish were separated by electrophoresis and transferred to a nylon membrane (Biodyne, ICN, Glen Cove, NY, USA). Detection of the signal was performed in accordance with the standard protocol for a nucleic acid detection kit (Roche). Northern blots were probed with human STS cDNA. The human STS cDNA in pSPORT-1 was linearized with SalI. Digoxigenin-labeled human STS probes were produced by in vitro transcription with $\mathrm{T} 7$ RNA polymerase and an RNA labeling kit (Roche).

\section{In vitro translation}

STS proteins were synthesized in vitro with an Sp6 RNA polymerase-based TNT-coupled reticulocyte lysate system (Promega) according to the manufacturer's manual. An amount of $500 \mathrm{ng}$ pSTS or truncated expression vector was mixed with in vitro translation reaction mixtures. Translation reactions were performed with SP6 TNT RNA polymerase for $90 \mathrm{~min}$ at $30{ }^{\circ} \mathrm{C}$. A volume of $10 \mu \mathrm{l} 2 \times$ SDS sample buffer was added to $10 \mu \mathrm{l}$ in vitro translated products, heated for $5 \mathrm{~min}$ and subjected to $12 \%$ $(\mathrm{w} / \mathrm{v})$ SDS-PAGE and then to Western blot analysis.

\section{Pulse-chase experiments}

COS-1 cells were transfected with pSTS $(2 \cdot 0 \mu \mathrm{g})$ or mutant STS expression vectors 1 day before metabolic labeling. COS-1 cells were incubated with methioninefree DMEM for $15 \mathrm{~min}$ and then labeled with ${ }^{35} \mathrm{~S}$ methionine $(0.4 \mathrm{mCi} / \mathrm{ml})$ for $30 \mathrm{~min}$. After labeling, the radioactive medium was replaced with DMEM containing $4 \mathrm{mM}$ methionine, and the cells were incubated for the indicated time. Then the cells were washed with PBS and scraped into $400 \mu \mathrm{l}$ RIPA buffer $(50 \mathrm{mM}$ Tris-HCl, $1 \%$ $(\mathrm{v} / \mathrm{v})$ Nonidet P-40, $0 \cdot 1 \%(\mathrm{w} / \mathrm{v})$ deoxycholate, $0 \cdot 1 \%$ (w/v) SDS, $150 \mathrm{mM} \mathrm{NaCl}, 1 \mathrm{mM}$ EDTA, $1 \mathrm{mM}$ dithiothreitol, $0.1 \mathrm{mM}$ PMSF and $1 \times$ proteinase inhibitor, Compete Mini (Roche)). Equal aliquots of protein from cell extracts were precleared with $20 \mu \mathrm{l}$ protein-G Sepharose (Amersham Pharmacia) for $30 \mathrm{~min}$ at $4{ }^{\circ} \mathrm{C}$. After centrifugation, supernatants were incubated with $1 \mu \mathrm{l}$ anti-STS serum for $3 \mathrm{~h}$ at $4{ }^{\circ} \mathrm{C}$ and then overnight on a rocking platform with $20 \mu \mathrm{l}$ protein-G Sepharose at $4{ }^{\circ} \mathrm{C}$. Immunocomplexes were washed four times by resuspension in $500 \mu \mathrm{l}$ RIPA buffer and collected by centrifugation. Pellets were resuspended in $10 \mu \mathrm{l} 2 \times \mathrm{SDS}$ sample buffer and then subjected to SDS-PAGE. Gels were dried and exposed to Fuji RX-U film.

\section{Coimmunoprecipitation with STS-FLAG fusion protein}

COS-1 cells were cultured in $100 \mathrm{~mm}$ plastic dishes and were transfected with the STS mutant and STS-FLAG fusion expression vectors with FuGENE 6. For coprecipitation, whole-cell extracts $(1 \mathrm{mg})$ from COS-1 cells in $400 \mu$ RIPA buffer were incubated with anti-FLAG IgG (Sigma) for $1 \mathrm{~h}$ at $4{ }^{\circ} \mathrm{C}$ in $500 \mu \mathrm{l}$ IP buffer 
(50 mM Tris- $\mathrm{HCl}(\mathrm{pH} 7 \cdot 4), 100 \mathrm{mM} \mathrm{NaCl}, 1.5 \mathrm{mM}$ EGTA, $0 \cdot 1 \%(\mathrm{v} / \mathrm{v})$ Triton X-100, $1 \mathrm{mM}$ DTT, $1 \mathrm{mM}$ PMSF and $1 \times$ protenase inhibitor). Then $20 \mu$ protein A Sepharose-FF (Amersham Pharmacia) were added, and the mixture was incubated overnight at $4{ }^{\circ} \mathrm{C}$. The bound complex was then washed three times with IP buffer. The precipitated proteins were eluted with $20 \mu \mathrm{l} 2 \times \mathrm{SDS}$ sample buffer containing $2 \%(\mathrm{v} / \mathrm{v})$ 2-mercaptoethanol (2-ME) and resolved on a 10\% (w/v) SDS polyacrylamide gel. Western blot analysis was performed with a rabbit polyclonal anti-STS serum at 1:1000 dilution. Some precipitated proteins were eluted with $100 \mu \mathrm{l}$ of $100 \mathrm{mM}$ glycine- $\mathrm{HCl}$ buffer $(\mathrm{pH} 3 \cdot 0$ ) and then neutralized with $100 \mu \mathrm{l}$ of $1 \mathrm{M}$ Tris- $\mathrm{HCl}(\mathrm{pH} 8 \cdot 0)$, and STS enzyme activity was assayed.

\section{Data analysis}

Values are presented as means \pm S.E One-way ANOVA was used to test differences in repeated measures across experiments. Significant results from ANOVA were further analyzed by Tukey's post-hoc test. $P<0 \cdot 05$ was considered significant.

\section{Results}

\section{Effect of terminal truncated STS}

To examine the effect of truncated STS on the enzyme activity, truncated STS expression vectors were transfected into COS-1 cells, which do not express endogenous STS enzymes, and STS enzyme activities were assayed (Fig. 2). The enzyme activity level of STS in the mock transfection was low. The activity level of STS in COS-1 cells transfected with truncated STS lacking the $\mathrm{N}$-terminal regions $(\triangle \mathrm{N} 1$ and $\triangle \mathrm{N} 2)$ or the C-terminal regions $(\triangle \mathrm{C} 1$ and $\triangle \mathrm{C} 2)$ was significantly lower $(P<0 \cdot 01)$ than that in COS-1 cells transfected with wild-type STS. The activity level of STS in COS-1 cells decreased greatly, depending on the number of missing amino acids in the truncated C-terminal region. The STS enzyme activity in COS-1 cells transfected with the $\triangle \mathrm{C} 2$ truncated expression vector that lacks $\mathrm{C}-52$ amino acids was only $5 \cdot 1 \%$ of that in COS- 1 cells transfected with wild-type STS and did not differ significantly from that in the mock transfection. When the truncated STS expression vectors that lack both the $\mathrm{N}$-terminal and $\mathrm{C}$-terminal regions $(\triangle \mathrm{N} 1 \mathrm{C} 2$ and $\triangle \mathrm{N} 2 \mathrm{C} 2)$ were transfected into COS-1 cells, STS enzyme activity was completely impaired.

To examine the protein expression of truncated STS in COS-1 cells, we performed Western blot analysis of extracts from COS-1 cells into which various kinds of truncated STS expression vectors had been transfected (Fig. 3A). The protein levels of the C-terminal truncated STS ( $\triangle \mathrm{C} 1$ and $\triangle \mathrm{C} 2)$ were almost the same as the levels of wild-type STS protein in COS-1 cells. When the

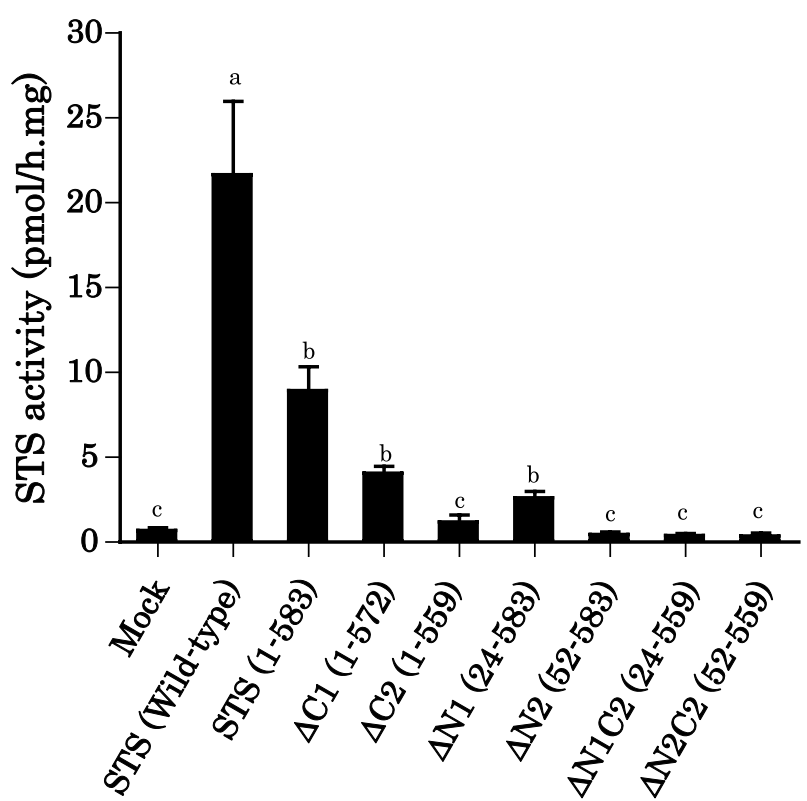

Figure 2 STS enzyme activity of truncated STS. pSV-SPORT-1 (Mock), STS (wild-type), STS (1-583), $\triangle \mathrm{C} 1$ (1-572), $\triangle \mathrm{C} 2$ (1-559), and $\triangle N 1, \triangle N 2, \triangle N 1 C 2$ and $\triangle N 2 C 2$ plasmids were transfected into COS-1 cells. STS activities in transfected cell extracts in STS lysis buffer (10 mM Tris-HCl, 1\% Triton-X, $1 \times$ proteinase inhibitor) were assayed. Values presented are means \pm S.E. of STS enzyme activities from four separate experiments. Different superscript letters indicate significant differences $(P<0 \cdot 05)$, as determined by ANOVA followed by Tukey's post-hoc test.

truncated STS lacking the C-terminal region was transfected into COS-1 cells, the protein translation was not impaired. On the other hand, the protein enzyme levels of truncated STS lacking the $\mathrm{N}$-terminal region $(\triangle \mathrm{N} 1$, $\triangle \mathrm{N} 2, \triangle \mathrm{N} 1 \mathrm{C} 2$ and $\triangle \mathrm{N} 2 \mathrm{C} 2$ ) decreased. The molecular sizes of truncated proteins detected by antihuman STS serum were smaller and the amounts of protein were less than those of wild-type STS. Several minor protein bands were also detected in COS-1 cells transfected with the $\mathrm{N}$-terminal truncated STS expression vectors. To examine the expression of truncated STS, we performed Northern blot analysis, using total RNA from COS-1 cells that had been transfected with truncated STS expression plasmids (Fig. 3B). STS mRNA levels were unaltered in COS-1 cells that had been transfected with truncated expression vectors. These observations suggest that truncated STS transcription has the same effect as that of wild-type STS.

To determine the effect of N-terminal truncated STS $(\triangle \mathrm{N} 1, \triangle \mathrm{N} 2, \triangle \mathrm{N} 1 \mathrm{C} 2$ and $\triangle \mathrm{N} 2 \mathrm{C} 2)$ on protein synthesis processes, we examined the efficiency of plasmid expression, using in vitro transcription/translation (Fig. 4). Translation products were subjected to SDS-PAGE and then to Western blot analysis. The amounts of STS translation products in in vitro transcription-translation reaction mixtures were determined. Although several 


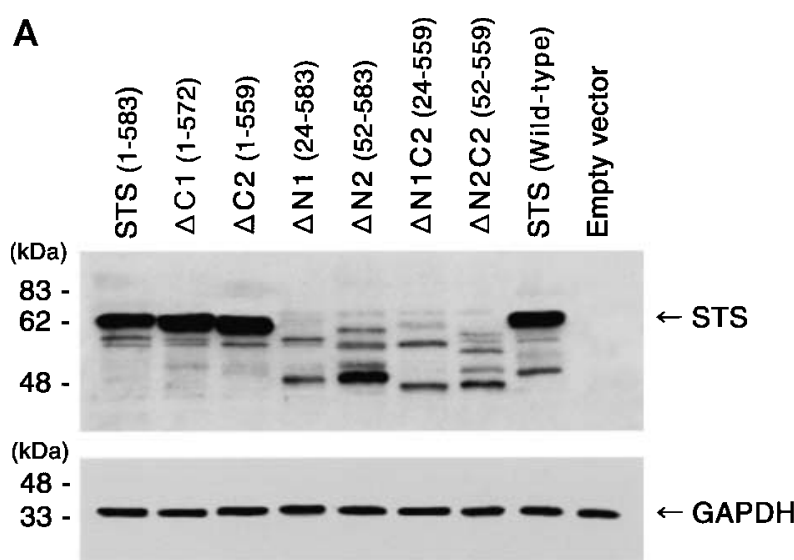

B

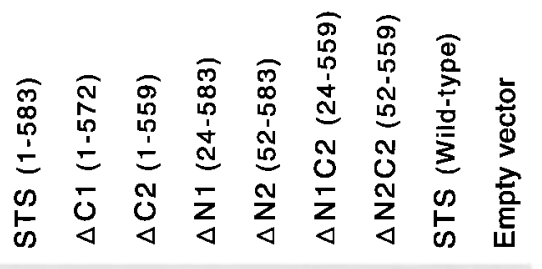

STS

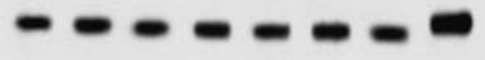

$18 S$ rRNA

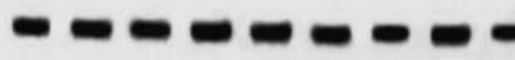

Figure 3 Truncated STS protein and STS gene expression. Truncated STS expression vectors were transfected into COS-1 cells with FuGENE 6. (A) A volume of $10 \mu \mathrm{g}$ cell extracts was subjected to Western blot analysis with anti-human STS serum. The membrane was stripped according to the supplier's protocol, and immunodetection was carried out with anti-human GAPDH IgG. (B) RNA was extracted from COS-1 cells after 24-h cotransfection treatment. Total RNA $(30 \mu \mathrm{g})$ was subjected to Northern blot analysis with wild-type human STS RNA probes.

minor bands were detected, the truncated STS lacking the $\mathrm{N}$-terminal signal peptides of STS $(\triangle \mathrm{N} 1$ and $\triangle \mathrm{N} 1 \mathrm{C} 2)$ had no apparent effect on protein synthesis, indicating that the $\mathrm{N}$-terminal regions of STS have only a small effect on translational processes in a cell-free system.

We performed pulse-chase experiments to determine whether a C-terminal one-base mutant STS (Q560P) and a C-terminal truncated STS $(\triangle \mathrm{C} 2)$ have effects on the synthesis and degradation of STS protein (Fig. 5). COS-1 cells were transfected with wild-type STS, $\triangle \mathrm{C} 2$ and Q560P expression plasmids and then metabolically labeled with ${ }^{35} \mathrm{~S}$-methionine. During a pulse period up to $24 \mathrm{~h}$, the labeled protein levels of wild-type STS and the $\triangle \mathrm{C} 2$ and Q560P mutants decreased with progress of time. The results of pulse-chase experiments on COS-1 cells that had been transfected with the one-base mutant Q560P and $\mathrm{N}$-terminal region-truncated STS were compared with
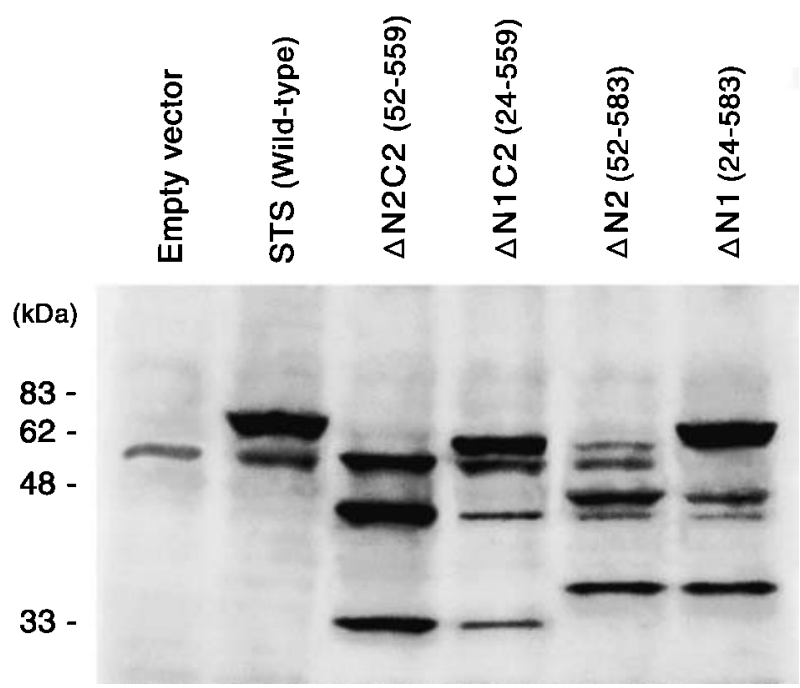

Figure 4 Truncated STS protein in an in vitro translation system. Translated proteins were synthesized in an in vitro system. A volume of $10 \mu \mathrm{l}$ of in vitro translated products was subjected to Western blot analysis with anti-human STS serum.

the results of pulse-chase experiments on COS-1 cells that had been transfected with a wild-type STS expression vector. The results showed that both the C-terminal one-base mutant and truncated mutant protein disappeared from COS-1 cells as fast as did wild-type STS. Thus, the degradation of STS protein is not affected by a C-terminal mutation of STS.

\section{Dominant negative effect of C-terminal STS mutant}

The STS enzyme activity in COS-1 cells that had been transfected with $\triangle \mathrm{C} 2$ or that in cells that had been transfected with Q560P was significantly $(P<0 \cdot 05)$ lower than that in cells that had been transfected with wild-type STS alone (Table 1). The enzyme activity levels in COS-1 cells into which Q560P had been introduced and in COS-1 cells into which $\triangle \mathrm{C} 2$ had been introduced were $2 \cdot 8 \%$ and $3 \cdot 5 \%$ respectively of the level in cells into which the wild-type STS alone had been transfected. The enzyme activity level in COS-1 cells into which both $1 \mu \mathrm{g}$ wild-type STS and $1 \mu \mathrm{g} \triangle \mathrm{C} 2$ truncated expression vector had been introduced was significantly $(P<0 \cdot 05)$ decreased compared with that in cells transfected with the wild-type STS alone. The enzyme activity level in cells into which both wild-type STS and $\triangle \mathrm{C} 2$ truncated had been introduced did not differ from that in cells transfected with both wild-type STS and Q560P. The enzyme activity levels in COS-1 cells that had been cotransfected with wild-type STS and $\triangle \mathrm{C} 2$ and in COS-1 cells that had been cotransfected with wild-type STS and Q560P were $37 \cdot 9 \%$ and $40 \cdot 8 \%$ respectively of the level in COS-1 cells that had been transfected with only wild-type STS. 

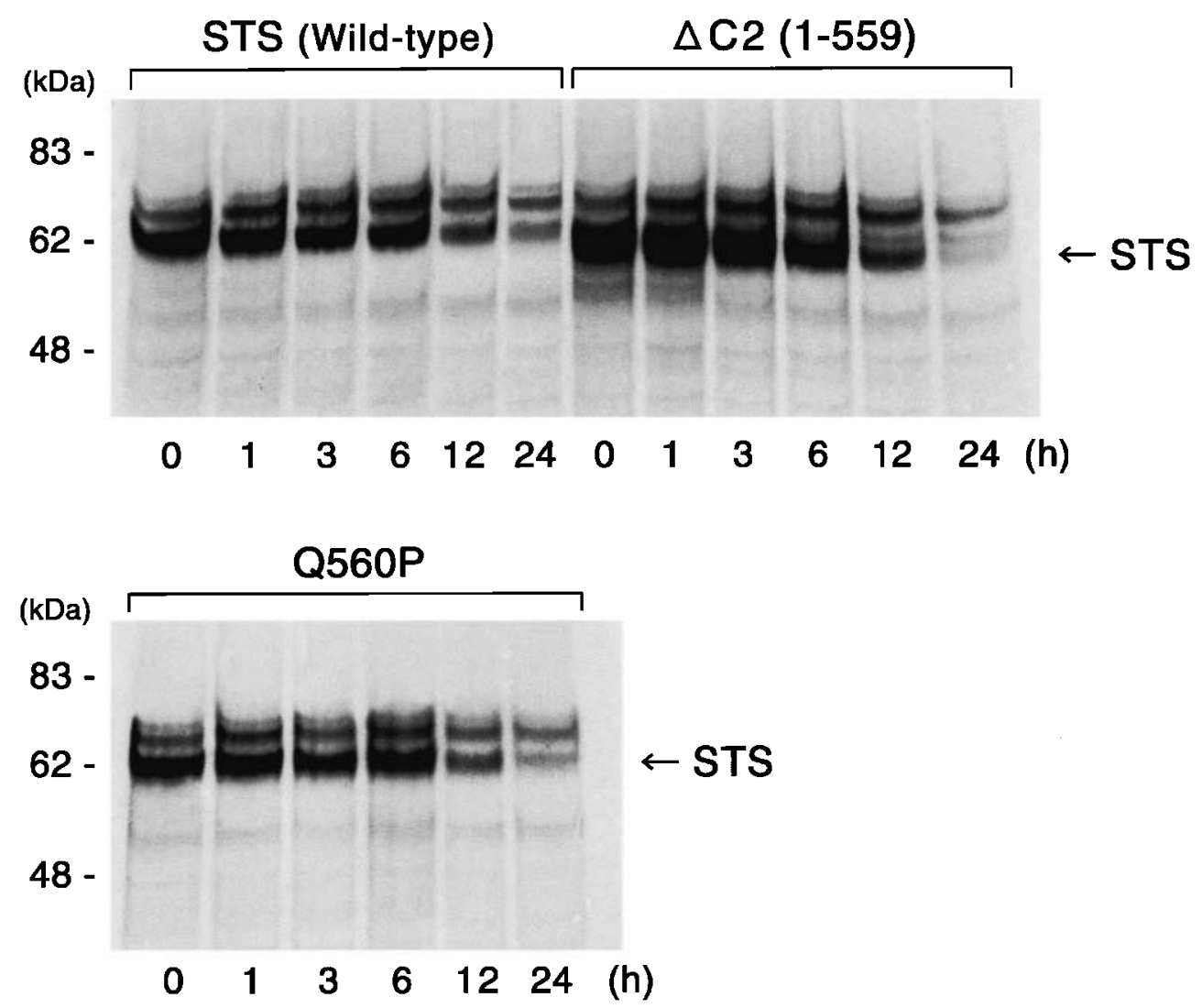

Figure 5 Results of pulse-chase experiments on transfection with wild-type STS (pSTS), mutant STS (pQ560P) and truncated STS $(\triangle \mathrm{C} 2)$ expression plasmids. COS-1 cells were transfected with pSTS, pQ560P and pSTSM1A6 ( $2 \mu \mathrm{g} /$ plate), using FuGENE 6. After transfection, COS-1 cells were pulse-labeled with ${ }^{35} \mathrm{~S}$-methionine for $30 \mathrm{~min}$ and then chased with an excess of cold methionine followed by immunoprecipitation with anti-human STS serum of the proteins and SDS-PAGE. Autoradiograms with wild-type STS, mutant STS (Q560P) and truncated STS $(\Delta C 2)$ are shown. Each experiment was performed on two separate occasions.

To determine the dose-dependent effect of $\triangle \mathrm{C} 2$ on the production of wild-type STS, $0 \cdot 01-3 \mu \mathrm{g} \triangle \mathrm{C} 2$ were cointroduced with $1 \mu \mathrm{g}$ wild-type STS expression vector

Table 1 C-terminal mutated STS reduced enzyme activity of wild-type STS

\begin{tabular}{lr} 
& $\begin{array}{c}\text { STS enzyme activity } \\
(\text { pmol/h.mg) }\end{array}$ \\
\cline { 2 - 2 } Plasmids & $1 \cdot 5 \pm 0 \cdot 5^{\mathrm{c}}$ \\
Mock & $31 \cdot 4 \pm 4 \cdot 5^{\mathrm{a}}$ \\
STS (Wild-type) & $0 \cdot 9 \pm 0 \cdot 5^{\mathrm{c}}$ \\
Q560P & $1 \cdot 1 \pm 0 \cdot 4^{\mathrm{c}}$ \\
$\triangle \mathrm{C} 2$ & $12 \cdot 8 \pm 5 \cdot 7^{\mathrm{b}}$ \\
STS +Q560P & $11 \cdot 9 \pm 1 \cdot 8^{\mathrm{b}}$ \\
STS $+\triangle$ C2 &
\end{tabular}

Values presented are means \pm S.E. of STS enzyme activities from three separate experiments.

Values with a different superscript letter are significantly different $(P<0 \cdot 05)$ from others. into COS-1 cells, and the rates of decrease in STS enzyme activity level were assayed (Fig. 6A). The levels of STS enzyme activity in COS-1 cells that had been cotransfected with $0.01,0.05,0.1$ and $0.5 \mu \mathrm{g} \triangle \mathrm{C} 2$ and $1 \mu \mathrm{g}$ wild-type STS decreased by $9 \%, 13 \%, 29 \%$ and $50 \%$ respectively. Truncated STS has a dominant negative effect on wild-type STS when both truncated STS and wild-type STS proteins exist in cells. To examine the effect of truncated STS on STS protein levels, we performed Western blot analysis of extracts from cells into which truncated STS and wild-type STS plasmids had been transfected (Fig. 6B). The levels of STS, including truncated STS, in COS-1 cells that had been transfected with wild-type STS and truncated STS were not affected by the amount of truncated STS protein.

To determine whether the C-terminal STS mutant has a dominant negative effect on wild-type STS, we cointroduced Q560P mutant expression vectors with wild-type STS expression vectors into COS-1 cells (Fig. 7). The levels of STS enzyme activity in COS-1 cells 
A

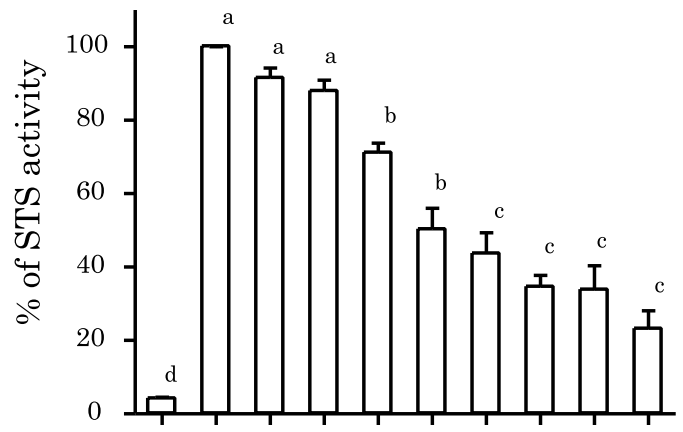

Empty vector $(\mu \mathrm{g}) 1$ STS (Wild-type) $(\mu \mathrm{g})$ $\Delta \mathrm{C} 2(1-559) \quad(\mu \mathrm{g})$ $\begin{array}{ccccccccc}1 & 1 & 1 & 1 & 1 & 1 & 1 & 1 & 1 \\ & 0.01 & 0.05 & 0.1 & 0.5 & 1.0 & 1.5 & 2.0 & 3.0\end{array}$

B

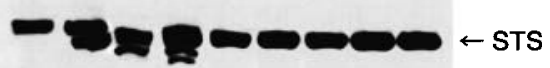

STS (Wild-type) -+++++++++

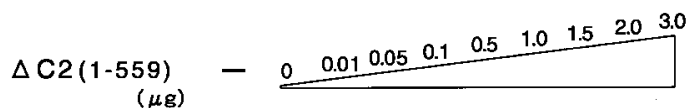

Figure 6 STS enzyme activity of truncated STS and wild-type STS in cells. (A) COS-1 cells were cotransfected with $1 \mu \mathrm{g}$ pSTS and increasing amounts of truncated STS expression vectors. Values presented are the means \pm S.E. of STS enzyme activities, expressed as a percentage of the wild-type STS activity, from four separate experiments. Different superscript letters indicate significant differences $(P<0 \cdot 01)$, as determined by ANOVA followed by Tukey's post-hoc test. (B) Western blot analysis was performed with COS-1 cell extracts, using anti-STS.

that had been cotransfected with $0 \cdot 01,0 \cdot 05,0 \cdot 1$ and $0.5 \mu \mathrm{g}$ Q $560 \mathrm{P}$ and $1 \mu \mathrm{g}$ wild-type STS decreased by $7 \%$, $17 \%, 24 \%$ and $51 \%$ respectively. Q506P has a dosedependent effect on STS enzyme activity in COS-1 cells transfected with wild-type STS. Q560P has a dominant negative effect on wild-type STS when both Q560P mutant STS and wild-type STS protein exist in cells.

\section{Dimer conformation of STS}

To investigate the dominant negative effect on wild-type STS, we performed immunoprecipitation with an STSFLAG fusion protein. Whole-cell extracts from COS-1 cells cotransfected with $\triangle \mathrm{C} 2$ and pSTS-FLAG were incubated with anti-FLAG IgG. The protein complex was precipitated with protein A Sepharose-FF. The protein complexes were subjected to $10 \%$ SDS-PAGE by running the gel under reducing conditions and were then analyzed by Western blotting with an STS antibody. As shown in Fig. 8A, FLAG antibody detected STS-FLAG fusion protein of mass $66 \mathrm{kDa}$ in cell extracts from COS-1 cells. As shown in Fig. 8B, STS antibody detected both STS-FLAG and $\triangle \mathrm{C} 2$ mutant protein in cell extracts.
Empty vector ( $\mu \mathrm{g}) 1$

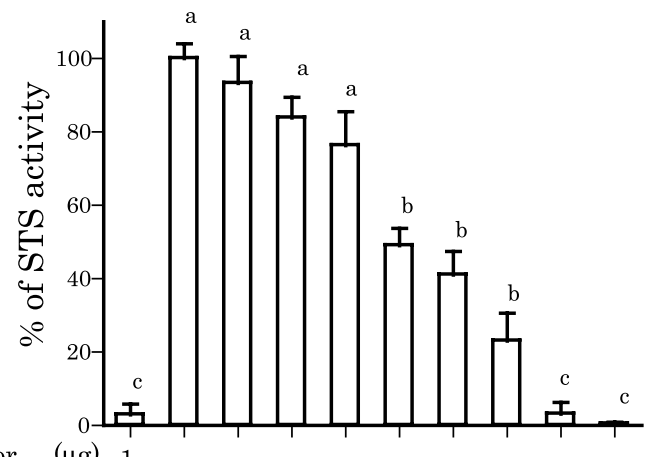

STS (Wild-type) $(\mu \mathrm{g})$

Q560P

$(\mu \mathrm{g})$

$\begin{array}{lllllllll}1 & 1 & 1 & 1 & 1 & 1 & 1 & 1 & 1\end{array}$

$\begin{array}{llllllll}0.01 & 0.05 & 0.1 & 0.5 & 1.0 & 1.5 & 2.0 & 3.0\end{array}$

Figure 7 STS enzyme activity of Q560P STS mutant and wild-type STS in cells. COS- 1 cells were cotransfected with $1 \mu \mathrm{g}$ pSTS and increasing amounts of pQ560P STS mutant expression vectors.

Values presented are the means \pm S.E. of STS enzyme activities, expressed as a percentage of the wild-type STS activity, from three separate experiments. Different superscript letters indicate significant differences $(P<0 \cdot 01)$, as determined by ANOVA followed by Tukey's post-hoc test.

$\triangle \mathrm{C} 2$ mutant protein was precipitated with STS-FLAG fusion protein (Fig. 8C). The coprecipitation results showed that STS-FLAG interacted with $\triangle \mathrm{C} 2$ mutant protein in cells. The results showed the STS forms a dimer conformation in cells.

To determine the dominant negative effect of Q560P, various amounts of $\mathrm{pQ} 560 \mathrm{P}$ were transfected into COS-1 cells with pSTS-FLAG $(0.5 \mu \mathrm{g} / \mathrm{plate})$ and pFLAG. Wholecell extracts from COS-1 cells cotransfected with expression plasmids were incubated with anti-FLAG IgG. The protein complex was precipitated with protein A Sepharose-FF. Precipitated proteins were eluted with $100 \mathrm{mM}$ glycine-HCl buffer (pH 3.0), and STS enzyme activity was assayed. The STS activity of COS-1 cells that had been transfected with pQ560P and the STS activity of COS-1 cells not transfected with pQ560P were compared (Fig. 9). The STS activity levels of COS-1 cells decreased by $50 \%, 71 \%$ and $78 \%$ when the cells were transfected with $0.12,0.25$ and $0.5 \mu \mathrm{g}$ pQ560P and $0.5 \mu \mathrm{g}$ pSTSFLAG respectively.

\section{Discussion}

STS is synthesized in the ER and is transported to the lumen side of the ER by translocation hydrophobic signal peptides on the N-terminal region of STS. N-terminal signal sequences are cleaved by signal peptidases that recognize Ser21-His22 or Ala23-Ala24 equally at the trans side of the membrane (von Heijne 1986). Lower levels of protein were detected when $\mathrm{N}$-terminal region-deleted STS protein expression vectors $(\triangle N 1, \triangle N 2, \triangle N 1 C 2$ and $\triangle \mathrm{N} 2 \mathrm{C} 2)$ were transfected into COS-1 cells. 


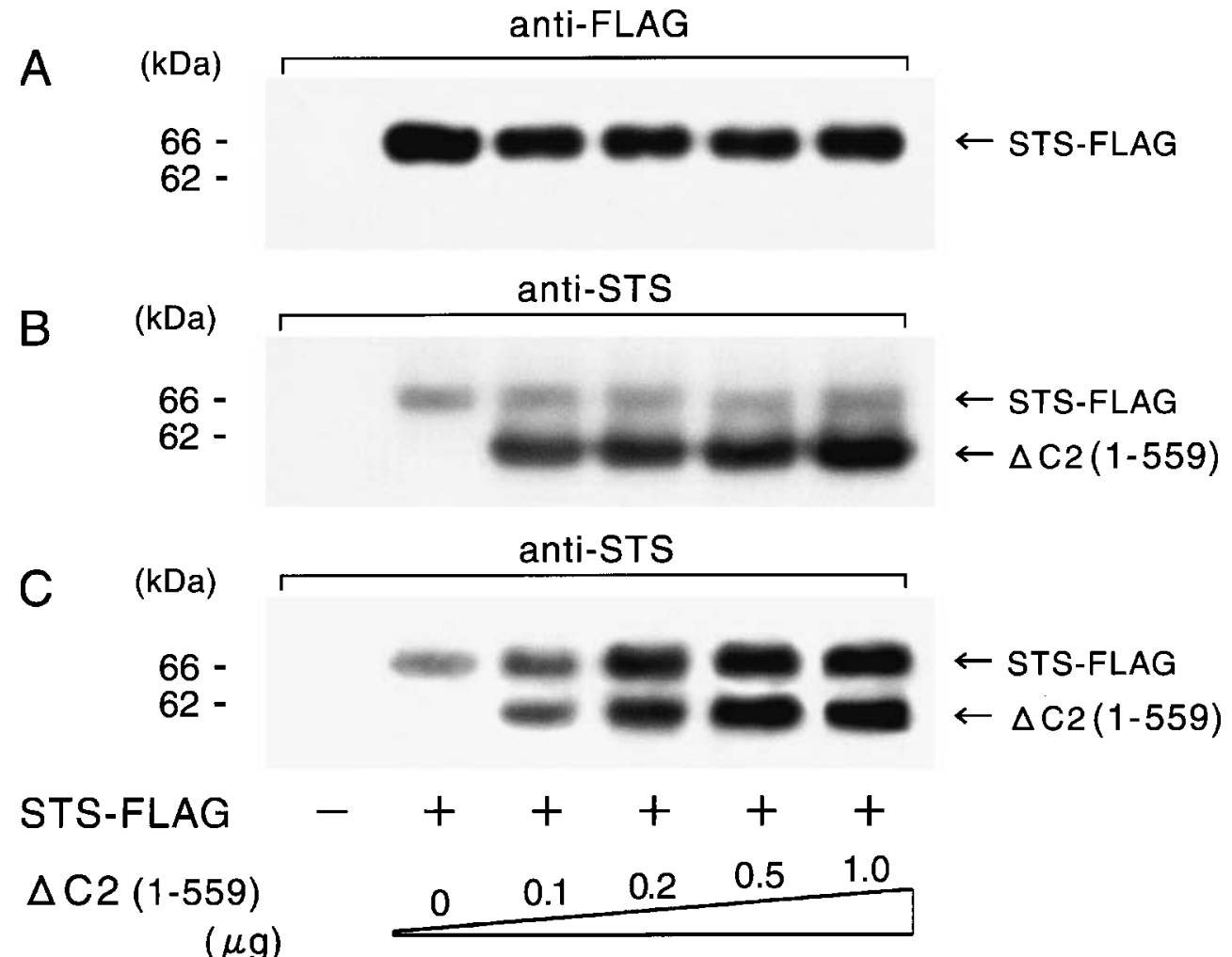

Figure 8 Interaction between STS-FLAG fusion protein and M1A6 STS mutant in cells. Whole-cell extracts were prepared from COS- 1 cells that had been transfected with $0 \cdot 12-1.0 \mu \mathrm{g} \triangle \mathrm{C} 2$ together with $0.5 \mu \mathrm{g}$ STS-FLAG fusion protein expression vector or an empty FLAG vector, so that the total amount of plasmids transfected in COS-1 cells was $1.5 \mu \mathrm{g}$. Preimmunoprecipitated cell extracts were subjected to $10 \%$ SDS-PAGE, and then Western blot analysis was performed with anti-FLAG (A) and anti-STS antibodies (B). Cell extracts were incubated with anti-FLAG IgG and immunoprecipitated by protein A Sepharose-FF. Washed beads were boiled in $2 \times$ SDS sample buffer containing 2\% 2-mercaptothanol, and precipitated proteins were resolved by SDS-PAGE and analyzed by Western blotting with an anti-STS antibody (C).

The enzyme activity level of truncated proteins decreased in proportion to the amount of protein. The steroidogenic associated enzyme P450c21 with an N-terminal region deletion produces small amounts of protein, and the $\mathrm{N}$-terminal hydrophobic domain has been shown to be important for protein stability (Hsu et al. 1993). $\mathrm{N}$-terminal signal peptide-deleted STS protein may not move to an appropriate intracellular position and may not fold properly in cells. Correct folding of a protein is important for its stability, since denatured proteins are known to be degraded more rapidly than are native forms (Pakula \& Sauer 1989). Proteins acquire their proper tertiary and quaternary structures by glycosylation in the lumen of the ER in mammals. The importance of $\mathrm{N}$-linked oligosaccharides in the folding of glycoproteins is widely recognized (Hurtley \& Helenius 1989). Two sites (Asn47 and Asn259) of the four potential $\mathrm{N}$-glycosylation sites of STS are used for glycosylation (Stein et al. 1989). Several minor protein bands that were detected in Western blots were thought to be degraded
STS proteins rather than nonspecific protein bands. Although in vitro translation reactions of both $\triangle \mathrm{N} 1 \mathrm{C} 2$ and $\triangle \mathrm{N} 1$ proceeded properly and the $\mathrm{N}$-terminal signal seems to have no influence on the translation, $\mathrm{N}$-terminal region-deletion mutants, $\triangle \mathrm{N} 2$ and $\triangle \mathrm{N} 2 \mathrm{C} 2$, which lack the $\mathrm{N}$-glycosylation site, may fail to fold properly and may degrade rapidly in cells. Several minor protein bands were thought to result in initiation of translation at internal downstream methionines.

Since the level of $\triangle \mathrm{N} 2 \mathrm{C} 2$ expression in an in vitro translation system is lower than that of $\triangle \mathrm{N} 2$, a lack of C-terminal regions also appears to have some effects on STS protein levels. Western blot analysis of C-terminal region-truncated STS proteins $(\triangle \mathrm{C} 1$ and $\triangle \mathrm{C} 2)$ has shown that the $\mathrm{C}$-terminal region does not affect protein expression, and the results of a pulse-chase experiment have shown that the $\mathrm{C}$-terminal region of STS $(\triangle \mathrm{C} 2)$ has no effect on protein degradation. The results of $\mathrm{x}$-ray crystallography of STS have recently been reported (Hernandez-Guzman et al. 2003). The STS structure 


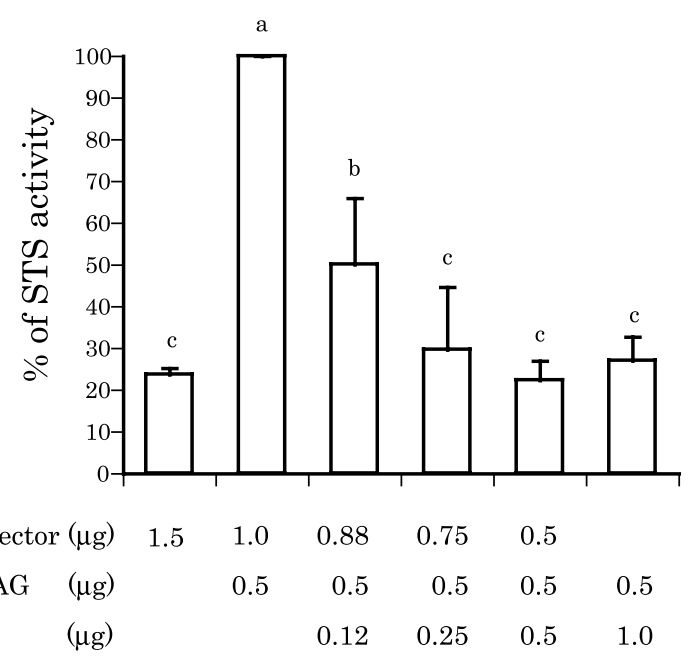

Figure 9 Dominant negative effects of STS enzyme activity of STS mutant. COS- 1 cells were cotransfected with $0.5 \mu \mathrm{g}$ pSTS-FLAG and increasing amounts of pQ560P STS. Cell extracts were incubated with anti-FLAG IgG and immunoprecipitated by protein A Sepharose-FF. Precipitated proteins were eluted with sodium acetate buffer, and STS enzyme activity was assayed. Values presented are the means \pm S.E. of STS enzyme activities, expressed as a percentage of the STS-FLAG activity, from three separate experiments. Different superscript letters indicate significant differences $(P<0.01)$, as determined by ANOVA followed by Tukey's post-hoc test.

consists of antiparallel $\beta$-helices that traverse the membranes and anchor the functional domain on the membrane surface facing the ER lumen. Therefore, the polar catalytic domain rests on the lumen side of the lipid bilayer. Residues from the membrane-associated region line the groove leading to the active site. Residues 468500 and $548-568$ constitute the entrance to the active site. These two residues are thought to be an important region for enzyme activity, and Q560P and truncated $\triangle \mathrm{C} 2$ mutant proteins lack STS enzyme activity in cells.

Dominant-negative mutations in membrane receptors or DNA-binding proteins, including oncogenes, have been reported (Herskowitz 1987). The binding ability of these proteins depends on the cooperation of two or more motifs belonging to different subunits. Although a dominant negative mutation is not usually expected for diseases involving defects of enzymes, since enzymes are so active that there is no loss of function unless their levels have decreased to less than $10-15 \%$ of normal levels, several dominantly inherited metabolic diseases have been reported (Xiao et al. 1995, Chamberlin et al. 1997). In a heterozygous state, these mutants antagonize the activity of the remaining wild-type allele and give a phenotype approaching a null. STS proteins form homodimer complexes (Iwamori et al. 1976, Gniot-Szulzycka \& Januszewska 1986). Mutant Q560P protein may not only fail to have the proper conformation like wild-type STS but also bind wild-type STS, alter catalytic domains and abrogate the enzyme activities. The mutant binds wildtype STS, and the stability of the whole heteroallelic complexes may be decreased. The sequence identity of STS was $32 \%$ of arylsulfatase A sequence. According to sequence alignment, codon Q560 is conserved in codon 486 of arylsulfatase A, and the shape, size and structure of that domain resemble those of the soluble form of human sulfatase (Lukatela et al. 1998). A nonsense mutation (Q486X) in the arylsulfatase A gene has been reported in a patient with metachromatic leukodystrophy (Harvey et al. 1994). This site is important for both sulfatase enzyme activity and structure of protein constructs because the C-terminal STS mutant has shown a dominant negative effect.

In this study, we have shown that both the $\mathrm{N}$-terminal regions and C-terminal region are important for STS enzyme activity. C-terminal region mutants have a dominant negative effect on the activity of wild-type STS. Since estrone sulfate is an important source of estrogens in postmenopausal women, development of inhibitors of estrone sulfatase activity may be of value in the treatment of hormone-dependent breast cancers. Plasmids that have a dominant negative effect on STS activity might be useful in treatment of hormone-dependent cancer. Future studies are needed to determine the application of this to cancer therapy.

\section{Acknowledgements}

The authors declare that there is no conflict of interest that would prejudice the impartiality of this scientific work.

\section{References}

Alperin ES \& Shapiro LJ 1997 Characterization of point mutations in patients with X-linked ichthyosis. Effects on the structure and function of the steroid sulfatase protein. Journal of Biological Chemistry 272 20756-20763.

Anderson C, Freeman J, Lucas LH, Farley M, Dalhoumi H \& Widlanski TS 1997 Estrone sulfatase: probing structural requirements for substrate and inhibitor recognition. Biochemistry 36 2586-2594.

Basler E, Grompe M, Parenti G, Yates J \& Ballabio A 1992 Identification of point mutations in the steroid sulfatase gene of three patients with X-linked ichthyosis. American Journal of Human Genetics 50 483-491.

Bond CS, Clements PR, Ashby SJ, Collyer CA, Harrop SJ, Hopwood JJ \& Guss JM 1997 Structure of a human lysosomal sulfatase. Structure $\mathbf{5} 277-289$

Chamberlin ME, Ubagai T, Mudd SH, Levy HL \& Chou JY 1997 Dominant inheritance of isolated hypermethioninemia is associated with a mutation in the human methionine adenosyltransferase $1 \mathrm{~A}$ gene. American Journal of Human Genetics 60 540-546.

Ciechanover A, Orian A \& Schwartz AL 2000 Ubiquitin-mediated proteolysis: biological regulation via destruction. Bioessays 22 442-451.

Cosma MP, Pepe S, Annunziata I, Newbold RF, Grompe M, Parenti G \& Ballabio A 2003 The multiple sulfatase deficiency gene encodes an essential and limiting factor for the activity of sulfatases. Cell 113 445-456. 
Dierks T, Schmidt B, Borissenko LV, Peng J, Preusser A, Mariappan M \& von Figura K 2003 Multiple sulfatase deficiency is caused by mutations in the gene encoding the human $\mathrm{C}(\mathrm{alpha})$-formylglycine generating enzyme. Cell 113 435-444.

Elias PM, Williams ML, Maloney ME, Bonifas JA, Brown BE, Grayson S \& Epstein EH Jr 1984 Stratum corneum lipids in disorders of cornification. Steroid sulfatase and cholesterol sulfate in normal desquamation and the pathogenesis of recessive X-linked ichthyosis. Journal of Clinical Investigation 74 1414-1421.

Gauthier R, Vigneault N, Bleau G, Chapdelaine A \& Roberts KD 1978 Solubilization and partial purification of steroid sulfatase of human placenta. Steroids 31 783-798.

Gniot-Szulzycka J \& Januszewska B 1986 Purification of steroid sulphohydrolase from human placenta microsomes. Acta Biochimica Polonica 33 203-215.

Harvey JS, Carey WF, Nelson PV \& Morris CP 1994 Metachromatic leukodystrophy: a non-sense mutation (Q486X) in the arylsulphatase A (ARSA) gene. Human Molecular Genetics 3207.

Hernandez-Guzman FG, Higashiyama T, Pangborn W, Osawa Y \& Ghosh D 2003 Structure of human estrone sulfatase suggests functional roles of membrane association. Journal of Biological Chemistry 278 22989-22997.

Herskowitz I 1987 Functional inactivation of genes by dominant negative mutations. Nature 329 219-222.

Howarth NM, Purohit A, Robinson JJ, Vicker N, Reed MJ \& Potter BV 2002 Estrone 3-sulfate mimics, inhibitors of estrone sulfatase activity: homology model construction and docking studies. Biochemistry 41 14801-14814.

Hsu LC, Hu MC, Cheng HC, Lu JC \& Chung BC 1993 The $\mathrm{N}$-terminal hydrophobic domain of $\mathrm{P} 450 \mathrm{c} 21$ is required for membrane insertion and enzyme stability. Journal of Biological Chemistry 268 14682-14686.

Hurtley SM \& Helenius A 1989 Protein oligomerization in the endoplasmic reticulum. Annual Reviews in Cell Biology 5 277-307.

Iwamori M, Moser HW \& Kishimoto Y 1976 Solubilization and partial purification of steroid sulfatase from rat liver: characterization of estrone sulfatase. Archives in Biochemistry and Biophysics 174 199-208.

Li PK, Pillai R, Young BL, Bender WH, Martino DM \& Lin FT 1993 Synthesis and biochemical studies of estrone sulfatase inhibitors. Steroids $\mathbf{5 8}$ 106-111.

Li PK, Pillai R \& Dibbelt L 1995 Estrone sulfate analogs as estrone sulfatase inhibitors. Steroids 60 299-306.

Li PK, Chu GH, Guo JP, Peters A \& Selcer KW 1998 Development of potent non-estrogenic estrone sulfatase inhibitors. Steroids 63 425-432.

Lukatela G, Krauss N, Theis K, Selmer T, Gieselmann V, von Figura K \& Saenger W 1998 Crystal structure of human arylsulfatase A: the aldehyde function and the metal ion at the active site suggest a novel mechanism for sulfate ester hydrolysis. Biochemistry 37 3654-3664.

Noel H, Plante L, Bleau G, Chapdelaine A \& Roberts KD 1983 Human placental steroid sulfatase: purification and properties. Journal of Steroid Biochemistry 19 1591-1598.

Oyama N, Satoh M, Iwatsuki K \& Kaneko F 2000 Novel point mutations in the steroid sulfatase gene in patients with X-linked ichthyosis: transfection analysis using the mutated genes. Journal of Investigative Dermatology 114 1195-1199.

Pakula AA \& Sauer RT 1989 Genetic analysis of protein stability and function. Annual Reviews in Genetics 23 289-310.

Parenti G, Meroni G \& Ballabio A 1997 The sulfatase gene family. Current Opinion in Genetics and Development 7 386-391.

Peters C, Schmidt B, Rommerskirch W, Rupp K, Zuhlsdorf M, Vingron M, Meyer HE, Pohlmann R \& von Figura K 1990 Phylogenetic conservation of arylsulfatases. cDNA cloning and expression of human arylsulfatase B. Journal of Biological Chemistry $2653374-3381$.

Plemper RK \& Wolf DH 1999 Retrograde protein translocation: ERADication of secretory proteins in health and disease. Trends in Biochemical Science 24 266-270.

Purohit A, Williams GJ, Howarth NM, Potter BV \& Reed MJ 1995 Inactivation of steroid sulfatase by an active site-directed inhibitor, estrone-3-O-sulfamate. Biochemistry 34 11508-11514.

Schmidt B, Selmer T, Ingendoh A \& von Figura K 1995 A novel amino acid modification in sulfatases that is defective in multiple sulfatase deficiency. Cell 82 271-278.

Shapiro LJ, Yen P, Pomerantz D, Martin E, Rolewic L \& Mohandas T 1989 Molecular studies of deletions at the human steroid sulfatase locus. PNAS 86 8477-8481.

Stein C, Hille A, Seidel J, Rijnbout S, Waheed A, Schmidt B, Geuze $\mathrm{H} \&$ von Figura K 1989 Cloning and expression of human steroid-sulfatase. Membrane topology, glycosylation, and subcellular distribution in BHK-21 cells. Journal of Biological Chemistry 264 13865-13872.

Sugawara T \& Fujimoto S 2004 The potential function of steroid sulphatase activity in steroid production and steroidogenic acute regulatory protein expression. Biochemistry Journal 380 153-160.

Sugawara T, Honke K, Gasa S, Tanaka T, Fujimoto S \& Makita A 1994 Serum levels of steroid sulfatase protein in gynecologic carcinomas. Clinica Chimica Acta 226 13-20.

Sugawara T, Shimizu H, Hoshi N, Fujimoto Y, Nakajima A \& Fujimoto S 2000 PCR diagnosis of X-linked ichthyosis: identification of a novel mutation (E560P) of the steroid sulfatase gene. Human Mutations (Online) 15296.

Sugawara T, Fujimoto Y \& Fujimoto S 2001 Molecular analysis of X-linked ichthyosis in Japan. Hormone Research 56 182-187.

Traupe H \& Ropers HH 1982 Cryptorchidism and hypogenitalism in $\mathrm{X}$-linked recessive ichthyosis vulgaris [letter]. Human Genetics 60206.

von Heijne G 1986 A new method for predicting signal sequence cleavage sites. Nucleic Acids Research 14 4683-4690.

Warren JC \& French AP 1965 Distribution of steroid sulfatase in human tissues. Journal of Clinical Endocrinology and Metabolism $25278-282$.

Willemsen R, Kroos M, Hoogeveen AT, van Dongen JM, Parenti G, van der Loos CM \& Reuser AJ 1988 Ultrastructural localization of steroid sulphatase in cultured human fibroblasts by immunocytochemistry: a comparative study with lysosomal enzymes and the mannose 6-phosphate receptor. Histochemistry Journal 20 41-51.

Xiao Q, Weiner H, Johnston T \& Crabb DW 1995 The aldehyde dehydrogenase ALDH2*2 allele exhibits dominance over ALDH2* 1 in transduced HeLa cells. Journal of Clinical Investigation 96 2180-2186.

Yen PH, Allen E, Marsh B, Mohandas T, Wang N, Taggart RT \& Shapiro LJ 1987 Cloning and expression of steroid sulfatase cDNA and the frequent occurrence of deletions in STS deficiency: implications for X-Y interchange. Cell 49 443-454.

Zettersten E, Man MQ, Sato J, Denda M, Farrell A, Ghadially R, Williams ML, Feingold KR \& Elias PM 1998 Recessive X-linked ichthyosis: role of cholesterol-sulfate accumulation in the barrier abnormality. Journal of Investigative Dermatology 111 784-790.

Received 7 November 2005

Accepted 15 November 2005

Made available online as an Accepted Preprint 22 November 2005 